\title{
Modeling Degradation of Tracks for Maintenance Planning on a Tram Line
}

\author{
Mohammad Yousefikia, Sara Moridpour, Sujeeva Setunge, and Ehsan Mazloumi \\ School of Civil, Environmental and Chemical Engineering, RMIT University, Melbourne, Australia \\ Email: \{mohammad.yousefikia, sara.moridpour, sujeeva.setunge\}@rmit.edu.au, ehsan.mazloumi@ hotmail.com
}

\begin{abstract}
There is a need among transportation maintenance decision makers for a better understanding of the long-term behavior of railroad tracks. The use of accurate techniques to predict track conditions increases track safety and maintenance effectiveness. This paper provides a review of degradation models relevant for railroad tracks. Furthermore, due to the lack of long term information on the condition development of tram infrastructures, presents the methodology which will be used to derive degradation models from the data of Melbourne tram network.
\end{abstract}

Index Terms - degradation modeling, maintenance planning, railroad track, tram track

\section{INTRODUCTION}

In the past, transport organizations generally focused on construction and expansion of networks. Traditional maintenance plans mainly based on the knowledge and experience of expertise, with the major goal of providing a high level of safety to the infrastructures without so much concern over economical issues. In recent years, after completing expansion of major part of networks and also limitations in transport sector budgets, the emphasis has increasingly shifted from developing new infrastructure to intelligently maintaining the existing ones. Therefore, efforts are being made to develop a unified framework for maintenance decision making process and the underlying idea is to reduce the operation and maintenance expenditure while still assuring high safety standards.

For mechanical equipment, deterioration can be very quick, and so the economic importance of failure is clear. In case of transportation infrastructures such as road pavements and rail tracks, although most of the time deterioration process is very slow, but it might lead to massive failures with an enormous financial lose. As a result it is very important to decide when and how to perform maintenance operations for such systems and how to allocate the resources (manpower, materials, machines and funds) to the parts of the system with highest need. For railway track networks some maintenance decision support systems have been developed during recent decades to compare different maintenance and renewal policies, reduce costs and

Manuscript received January 6, 2014; revised March 62014 improve reliability decades (eg.Ref.[1]-[6]). While for railway track for different geometrical degradation modes and component deterioration the relation with the track load, time, speed of vehicles and other affecting parameters has been studied, the knowledge on degradation analysis and modeling of tram/LRT ${ }^{1}$ tracks has been rudimentary. This knowledge on rail track deterioration, results in different decision support models allowing an optimization of maintenance operations, for long, mid and short term planning of tram/LRT tracks.

The track condition data of Melbourne tram network was for a long time only gathered through inspection onsight and stocked in a non-digitized way. In the past, based on these data and experience of expertise, accumulated over many years, track maintenance operations were traditionally planned. With the introduction of new track inspection vehicles that run through track and detect a large amount of data from infrastructure condition, developing a framework for maintenance decision making of Melbourne tram network seems to be necessary.

Due to the lack of long term information on the condition development of light rail infrastructures, this study focuses on the result of the track inspections, Combined with information on the use of the track (traffic parameters) and other significant parameters (e.g. characteristics of the curves, type of rail profiles) to compose a model for forecasting track conditions. Based on the degradation model, maintenance and renewal operations will be optimized with respect to total cost of maintenance. This paper will present the first results from the literature study on this subject and the methodology which will be used to derive models from the data.

This paper is organized as follows: after the introduction, a description of the railroad tracks (including train and tram) characteristics, degradation process and maintenance operations are presented. In Section III, the track degradation modeling approaches are outlined. In Section IV stochastic models will be surveyed, together with the methodology which is chosen for this study (Section V).

${ }^{1}$ Light Rail Transit (LRT) is usually used to describe modern low floor trams operating in a right of way separate from other vehicle traffic. Trams are generally considered to be older vehicles often with steps to access the cab. These tend to operate in on-street or "streetcar" contexts but can have some degree of segregated right of way. "Streetcar" operations have an on-street right of way track shared with private car and freight vehicle traffic[7] 


\section{RAILROAD TRACKS}

A railroad or railway is a track where the vehicle travels over two parallel rails. The rails support and guide the wheels of the vehicles, which are traditionally either trains or trams. The aim of this section is to investigate the characteristics, degradation mechanism, quality indices, and operations carried out to improve quality of train and tram tracks.

\section{A. Railroad Track Characteristics}

The most common type of rail tracks are traditional ballasted track and concrete slab track (ballast less track) [8].On traditional ballasted track, the rail is mounted onto a wooden or concrete sleeper. The sleeper sits on a bed of ballast which distributes the loading to the subgrade. Top ballast is placed between the sleepers and on the shoulders to provide longitudinal and lateral stability (Fig. 1). The nature of ballasted track necessitate that the track can and will move under load; routine maintenance (especially tamping) is always required to restore line and level, and clean or replace ballast regularly. In addition to this ballasted track is a massive structure that makes it impossible to be used in tunnels, subway and especially in the urban roads as the tram track.

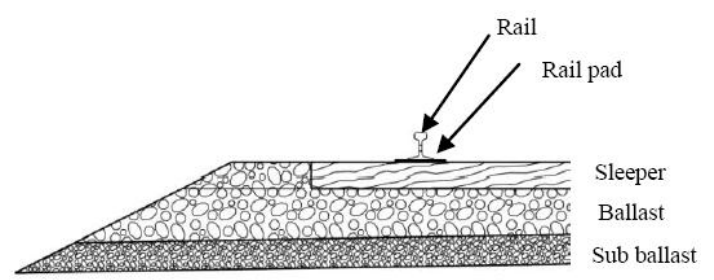

Figure 1. Configuration of typical ballasted train track

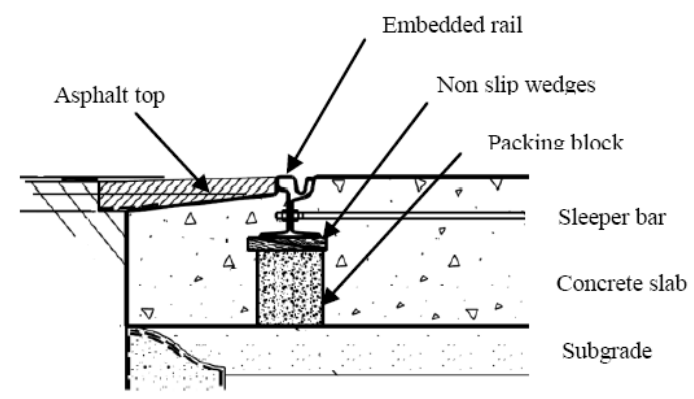

Figure 2. Configuration of typical tram track

In concrete slab track systems, the ballast is replaced by a rigid concrete slab track which transfers the load and provides track stability. Resilience is introduced into the track system by means of elastomeric components. There are different types of slab track systems that the most common type which is used is the embedded rail slab track. This kind of slab track with grooved rails is used because the surface is shared with road vehicles or pedestrian zones or sidewalks, so the track often has to be flush with road surface or pavement. Fig. 2 shows a typical tram track with embedded grooved rail.

\section{B. Railroad Track Degradation}

The degradation of rail track geometry is usually quantified in terms of seven track geometry defects: The left/right longitudinal level defects (LLL/RLL), the left/light horizontal alignment defects (LHA/RHA), cant defects (C), gauge deviations (GD) and track twist (T). They are measured using automated measuring systems, and saved as digitalized data. Many infrastructure decision makers tend to combine all these defects into track quality index which is typically a function of the standard deviations of each defect and/or vehicle's permissible speed. For further studies on track quality indices refer to [9]-[12].

In horizontal curves when a vehicle turns, the outer wheels have to travel further than the inner wheels, but rail vehicle wheels are usually mounted on a solid axel so they turn at the same speed. On a road vehicle, this is usually achieved by allowing the wheels to move independently, and fixing the front wheels in an arrangement known as Ackermann steering geometry. Trains and trams can turn corners without wheel-slip because the outer horizontal part of the wheels has a slightly tapered rim. The guide flange (ridge) is on the inside to prevent the vehicle from slipping sideways off the rails. The horizontal (cone-shaped) rim makes contact with the slightly convex top of a steel rail in different horizontal places so that the outer wheel has a larger effective diameter than the inner wheel [13]. With both tram and train wheels, this happens naturally because the tires are cone shaped sloping surfaces: the inside diameter is a few millimeters larger than the outside. As the track starts to curve, the train tries to run straight. The wheel flange presses against the side of the curved rail so the "contact point" between rail and wheel moves a few millimeters outwards, making the effective diameter of the outer wheel temporarily larger, and equally opposite: the effective diameter of the inner wheel effectively becomes temporarily smaller. This technique works well on large-radius curves which are canted, but not as well on tight curves. Larsson (2004) studied wear mechanism of rail as a function of curve radius and showed rail degradation in tight curves due to rail wear is an important issue in railway infrastructure.

City trams often use very tight curves, sometimes with a radius of much less than about 50 meters, and canting may be impossible because the track surface has to be flush with the road surface. In this respect, investigating track deterioration in tram curves due to rail wear is a major concern for maintenance decision makers.

\section{DEGRADATION MODELING}

So far, the railroad track characteristics and its degradation have been briefly described. However, moving on to the realm of modeling will help form the basis in the maintenance optimization procedure described later. Track inspection data provide maintenance decision makers with information on the current condition of the track. This data can be used to develop models that predict future track conditions and provide information for planning of maintenance and rehabilitation interventions. 
There are two general approaches for track degradation modeling: mechanistic and statistical models. Mechanistic approach use fundamental theories of infrastructure behavior for modeling, while the statistical approach involves the analysis of many observations of actual track performance and corresponding casual parameters. These two approaches and their contributions in track degradation modeling are outlined in this section.

\section{A. Mechanistic Approach}

Several attempts have been made to make mechanistic models based on laboratory studies to explain the track degradation process. Four models explaining mechanistic track degradation approach that are widely used in practical applications around the world are surveyed in this paper:

- An empirical track settlement model based on Japanese studies [14].

- A series of equations predicting settlement rate from ballast pressure based on experiments at the Technical University of Munich [15]

- An Austrian model looking at development of track quality from passenger's point of view [16]

In early 1960, studies on track deterioration due to ballast settlement when subject to cyclic loading were initiated in Japan $[17,18]$. The following equation is used to estimate the track settlement, $y$, due to their model developed from laboratory studies [14]:

$$
y=\gamma\left(1-e^{-\alpha x}\right)+\beta x
$$

where $x$ is the repeated number of loadings or tonnage carried by the track, $\alpha$ is the vertical acceleration required to initiate slip and can be measured using spring loaded plates of the ballast material on a vibrating table, $\beta$ is a coefficient proportional to the sleeper pressure and peak acceleration experienced by the ballast particles and is affected by the type and condition of the ballast material and the presence of water, and $\gamma$ is a constant dependent on the initial packing of the ballast material. As (1) represents, the most important variables according to Japanese model are traffic, time, track condition, and humidity.

This Choice of variables is supported by German model with some changes. German model do not considers humidity; however it regards vehicle characteristics as an important variable. Experiments under well controlled laboratory conditions at the Technical University of Munich representative of vehicles passing a dipped joint have been used to establish equations to calculate rate of settlement, $S$ [15]. The ballast pressure is multiplied by the $\log$ of the number of axle passes as follows:

$$
S=a \times p \times \ln \Delta N+b \times p^{1.21} \times \ln N
$$

The first term represents the fast settlement just after a maintenance action. $\Delta N$ expresses a pre loading period comprising the first passing axles. $\Delta N$ should be $<10000$ and $N$ in the second part should express the total number of passing axles. $\mathrm{P}$ is ballast pressure could be calculated with the Zimmermann method [15]. The parameters $a$, and $b$ are constants suggested to be in the value range; 1.57-2.23 and 3.04-15.2 respectively.

TU Graz has examined settlement developments in Austria by a quality index, which represents accelerations in the vehicle caused by track irregularities [19]. This index comprises of both horizontal and vertical deviations in tracks together with a lack of super elevation and speed [16]. An exponential development of track quality index over time was found giving the following expression for track quality:

$$
Q=Q_{0} \times e^{-b \times t}
$$

where $\mathrm{Q}$ is the track quality index and Q0 is the initial track quality. The Austrian exponential model says that the rougher the track becomes the more dynamic forces are created when trains pass, which increases the settlement.

Although mechanistic approach provides a good engineering understanding of how track responds to vehicle loading, it relies on mechanical properties of track parameters which are difficult to quantify and is very different from place to place. The result is that when mechanistic models are used to predict track degradation, considerable predictive errors are expected. On the other hand, the statistical approach involves the analysis of many observations of actual track condition and the corresponding causal parameters. When actual observations are used for modeling, more realistic prediction of track condition is expected to be given comparing to the mechanistic approach. Thus when a large amount of recorded data is available, it is preferred to use statistical approach for track degradation modeling.

\section{B. Statistical Approach}

Aim of statistical based degradation models is to find a general pattern for the statistical distribution of the track geometry using inspected data of track condition. Primary investigations to understand the fundamentals of deterioration mechanism of railroad track were carried out by the Office for Research and Experiments (ORE) of the International Union of Railways $\left(\right.$ UIC $^{2}$ ) in the 1980s [8].The ORE examined data available from a number of administrations and proposed a model that divided into two parts: the first part describes the deterioration directly after tamping, $\mathrm{e}_{0}$, and the second part describes the deterioration depending on traffic volume $\mathrm{T}$, dynamic axle load $2 \mathrm{Q}$ and speed $\mathrm{v}$. The relationship reads:

$$
e=e_{0}+h T^{\alpha}(2 Q)^{\beta} v^{\gamma}
$$

where $\mathrm{h}$ is a constant and the parameters $\alpha, \beta$, and $\gamma$ have to be estimated from experimental data. The ORE model have been analyzed on the data obtained from American and Indian Railways by [20] and [21], respectively.

Zwanenburg conducted statistical analyses on the Swiss Federal Railways network to retrieve the lifetime expectancy of complete railway switch and crossing system and their respective components [22]. He conducted single parameters analyses and multi parameters analysis on switch and crossing life

\footnotetext{
${ }^{2}$ Union Internationale des Chemins de fer
} 
expectancy. From the single parameters analysis, it can be concluded that 4 parameters including; soil quality, switch angle, percentage of freight trains and speed have an effect on the life time distribution of standard turnouts. For multi parameter analysis, it could be derived that the percentage of freight trains and the frog angle have some significant effects. Model results are presented in (5).

$$
y=s+\alpha x_{1}+\beta x_{2}+\gamma x_{3}+\delta x_{4}
$$

where $y$ is life time expectancy of switch and crossing $\mathrm{x}_{1}$ is percentage of freight trains, $x_{2}$ is frog angle, $x_{3}$ is a variable related to soil quality of subgrade and $x_{4}$ is speed. More recently, several approaches have been proposed to capture the nonlinear characteristics of track quality deterioration [4], [23], [24].

\section{StOchastic TRACK DEgRAdATION MODELING}

It would be helpful to look at the rail track from the stochastic point of view. The track is considered to be reliable when it performs its intended function under operating conditions for a specific period of time. When this is not the case, the track fails. The probability that the track will fail in a small time interval, is called the hazard rate. The concept of the hazard rate is involved in many methods and approaches to maintenance analysis [25][27]. The hazard rate function can have several behaviors. As far as the railroad is concerned, the most likely character is the so-called bathtub curve, as shown in Fig. 3.

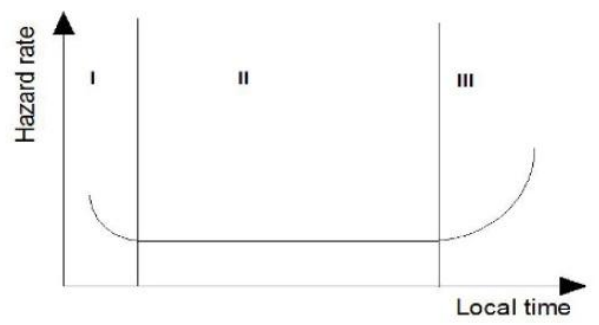

Figure 3. Bathtub curve with a local time-dependent hazard rate [28]

During the early life of an item (I), there are early failures caused by initial weakness or defects in material, poor quality control, inadequate manufacturing methods, human error, initial settlement, etc. Early failures show up early in the life of an item and are characterized by a high failure rate in the beginning, which keeps decreasing as time elapses. During the second part of the bathtub curve (II), the hazard rate is approximately constant. This period of life is known as the useful life during which only random failures occur. After the useful life the wearout period starts (III), when the failure rate increases. The causes for these wear-out failures include wear due to aging, fatigue cracking, corrosion and creep, poor maintenance, wear due to friction, and incorrect overhaul practices.

In the degradation models, a limit called critical failure progression is defined. This is a limit saying that degradation passing this limit is assumed to be critical. However, in real life there often exists more than just one level. The failure progress can be specified in various ways. The most common used model for the failure progression is the Gamma process which is a continuous time stochastic processes. For further info on systems with gamma deterioration process refer to [29]. A limitation of these processes is that the degradation is assumed to be linear with time. This is some time problematic when, for example rail cracks are modeled, since the failure progression is believed to go faster and faster as the crack size increases.

An alternative approach is to base the analysis on Markov models. By using Markov models a wide range of dependencies can be taken into account. Shafahi [30] developed a Markov model where the track quality index is calculated in a range of $0-100$ based on the track unevenness, twist, alignment and gauge measurements. The 100 unit range was then mapped onto 5 states in the Markov model. Transition probabilities for the transition matrix were then established from changes in the track quality index over time. An alternative 50-state Markov model is proposed by Lyngby [26] to represent the variation of twist over time. In this treatment each of the states represents the twist on a section of track up to $50 \mathrm{~mm}$. Alternative deterioration rates were given for the model depending on whether the track section was straight, curved or a transition section. The model also was used to optimize the frequency between track geometry inspections. Prescott [31] proposed a model that considers the degradation, inspection and maintenance of a single one eighth of a mile section of UK railway track. A Markov model of such a section is produced. Track degradation data from the UK rail network has been analysed to produce degradation distributions which are used to define transition rates within the Markov model. The model considers the changing deterioration rate of the track section following maintenance and is used to analyse the effects of changing the level of track geometry degradation at which maintenance is requested for the section. Reliability, Availability, Maintainability and Safety (RAMS) approaches to rail failure modeling are also used by Podofillini et al [32].

\section{A Degradation Model for the Melbourne TRAM TRACK}

Determining optimal maintenance during a planning horizon, while satisfying certain constraints in a railway system, is the objective of this study. To reach this objective, a Markov model for track deterioration is chosen and applied to Melbourne tram data.

Victorian public transport corporation defines three limits for track condition to ensure the safe operation of tram service [33]. A maintenance limit (C) indicates further investigation, an action limit (B) says that maintenance is required, and finally safety limit (F) says operational restriction is required. The first degraded state, denoted "C", is for minor degraded failures. When a "C" fault is found in track a speed restriction will be imposed, the inspections are made more frequently and maintenance intervention is desirable but not mandatory. When a " $\mathrm{B}$ " fault is found in a track section, in addition 
to speed restriction prompt maintenance intervention is required. Finally when an " $F$ " fault is found, that section of track is considered condemned. The critical failure due to degradation can be avoided by preventive maintenance if they are found in inspection intervals. In order to model the maintenance of the degradation failures, the degradation states will be split, according to whether these states are inspected or not. A subscript $u$ on the degraded states indicates that a degraded failure is undetected. Likewise, a subscript $d$ indicates a degraded failure is inspected. The Markov diagram is presented in Fig. 4, which is valid for the complete inspection interval. Note that, if it is inspected that the line is in the state $\mathrm{C}$, then the next inspection interval will start in state $C_{d}$.

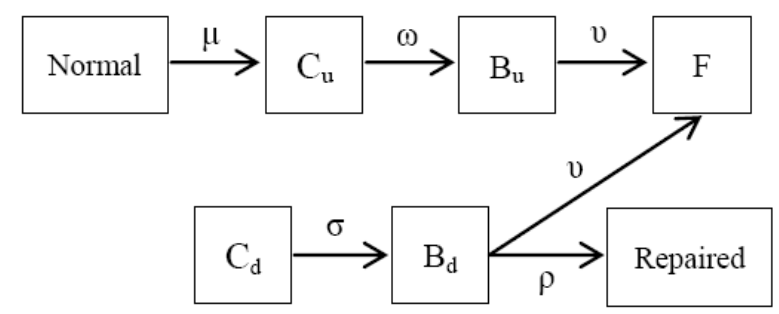

Figure 4. Markov model adapted to the melbourne tram track

where $\mathrm{C}_{\mathrm{u}}$ and $\mathrm{B}_{\mathrm{u}}$ are undetected minor and major degraded failures, respectively. Likewise, $C_{d}$ and $B_{d}$ are detected minor and major degraded failure, respectively. Note that the modeling allows transition from $\mathrm{C}$ to $\mathrm{B}$ to have different rates $(\omega, \sigma)$, depending on whether the degradation to $\mathrm{C}$ is detected or not. But the rate of failure (to $F$ ) is assumed to be the same for both $B_{u}$ and $B_{d}(v)$. Using transition rates make it possible to write the intensity matrix, of this time continues Markov chain, numbering the states as Normal $=1, \mathrm{C}_{\mathrm{u}}=2, \mathrm{C}_{\mathrm{d}}=3, \mathrm{~B}_{\mathrm{u}}=4$, $\mathrm{B}_{\mathrm{d}}=5, \mathrm{~F}=6$ and Repared $=7$.

\section{CONCLUSION}

Transportation agencies have historically focused on major construction and expansion of infrastructure. However, recently the emphasis has drastically shifted from development of new infrastructure to intelligently maintaining the existing ones. Despite having the largest urban light rail network of the world in Melbourne, its maintenance planning system is traditionally based on the experience of expertise. This paper presents a model which is currently in development to assess tram track conditions and predict required maintenance operations. It describes a degradation mechanism through various states and uses a combination of time continues and time discrete Markov chain.

\section{REFERENCES}

[1] R. E. Rivier, "Ecotrack : A tool for track maintenance and renewal managers," in Computers in Railways VI, C. A. Brebbia, Editor, WIT Press: United Kingdom, 1998, pp. 1120.

[2] S. Simson, L. Ferreira, and M. Murray, "Rail track maintenance planning: An assessment model. transportation research record," Journal of the Transportation Research Board, vol. 1713, p. 29-35, 2000 .
[3] G. Budai, D. Huisman, and R. Dekker, "Scheduling preventive railway maintenance activities," Journal of the Operational Research Society, vol. 57, no. 9, pp. 1035-1044, 2005.

[4] J. Sadeghi and H. Askarinejad, "Development of improved railway track degradation models," Structure and Infrastructure Engineering, no. 6, pp. 675-688, 2010.

[5] F. Peng and Y. Ouyang, "Track maintenance production team scheduling in railroad networks," Transportation Research Part B. Methodological, vol. 46, no. 10, pp. 1474-1488, 2012.

[6] T. Zhang, J. Andrews, and R. Wang, "Optimal scheduling of track maintenance on a railway network," Quality and Reliability Engineering International, vol. 29, no. 2, pp. 285-297, 2013.

[7] G. Currie and M. Burke, "Light rail in australia - performance and prospects," in Australasian Transport Research Forum, Brisbane, Australia, 2013.

[8] C. Esveld, "Modern railway track," in the Netherlands: MRT Productions Zaltbommel, ed. n. Ed., 2001.

[9] M. El-Sibaie and Y.-J. Zhang, "Objective track quality indices. transportation research record," Journal of the Transportation Research Board, vol. 1863, no. 1, pp. 81-87, 2004.

[10] J. Zhao, et al., "Optimizing policies of railway ballast tamping and renewal. transportation research record," Journal of the Transportation Research Board, vol. 1943, no. 1, pp. 50-56, 2006.

[11] H. Chang, R. Liu, and W. Wang, "Multistage linear prediction model of track quality index," in Traffic and Transportation Studies, pp. 1183-1192, 2010.

[12] J. Sadeghi, "Development of railway track geometry indexes based on statistical distribution of geometry data," Journal of Transportation Engineering, vol. 136, no. 8, pp. 693-700, 2010.

[13] M. A. Heckl and I. D. Abrahams, "Curve squeal of train wheels, Part 1: Mathematical model for its generation," Journal of Sound and Vibration, vol. 229, no. 3, pp. 669-693, 2000.

[14] Y. Sato, "Japanese studies on deterioration of ballasted track," Vehicle System Dynamics, vol. 24(sup1), pp. 197-208, 1995.

[15] K. Demharter, "Setzungsverhalten des gleisrostes unter vertikaler lasteinwirkung," der Technischen Univerität München: Minchen, Deutschland, 1982.

[16] R. Hummitszch, "Calculation schemes for MDZ and "modified standard deviation," Technical University of Graz: Austria, 2005.

[17] Y. Satoh, Experiment on Ballast Settlement due to Repeated Loading, in Railway Technical Research Report, Japan, 1959.

[18] Y. Satoh, A. Onishi, and S. Tanaka, Experiment on Grading of Crushed Stone Ballast, in Railway Technical Research Report, 1961.

[19] P. Veit, "Track quality - luxury or necessity? Qualität im gleis luxus oder notwendigkeit?" vol. 57, no. 12, pp. 32-37, 2006.

[20] J. Corbin and W. Kaufman, Classifying Track by Power Spectral Density, 1975

[21] P. Subramanian and O. Kumar, "Power spectral density for track irregularities," Indian Railway Technical Bulletin, vol. 35, no. 210, 1978.

[22] W.-J. Zwanenburg, Modelling Degradation Processes of Swiches and Crossing for Maintenance and Renewal Planning on the Swiss Railway Network, in Civil Engineering, Ecole Polytechnique Federale de Lausanne, 2009.

[23] L. Ubalde, et al., "Track deterioration in high-speed railways: Influence of stochastic parameters," in Proc. Railway Engineering, 2005.

[24] P. Veit, "Track quality-Luxury or necessity? RTR special: Maintenance \& renewal," Railway Technical Review, pp. 8-12, 2007.

[25] R. Mishalani and S. Madanat, "Computation of infrastructure transition probabilities using stochastic duration models," Journal of Infrastructure Systems, vol. 8, no. 4, pp. 139-148, 2002.

[26] N. Lyngby, P. Hokstad, and J. Vatn, "RAMS management of railway tracks," in Handbook of Performability Engineering, K. Misra, Editor, Springer London, 2008, pp. 1123-1145.

[27] J. A. Zakeri and S. Shahriari, "Developing a deterioration probabilistic model for rail wear," International Journal of Traffic and Transportation Engineering, vol. 1, no. 2, pp. 13-18, 2012.

[28] R. Ahmad and S. Kamaruddin, "An overview of time-based and condition-based maintenance in industrial application," Computers \& Industrial Engineering, vol. 63, no.1, pp. 135-149, 2012.

[29] C. Meier-Hirmer, et al., "Maintenance optimization for a system with a gamma deterioration process and intervention delay: Application to track maintenance," Proceedings of the Institution 
of Mechanical Engineers $O$, Journal of Risk and Reliability, vol. 223, no. 3, pp. 189-198, 2009.

[30] Y. Shafahi and R. Hakhamaneshi, "Application of maintenance management model for Iranian railways based on the Markov chain probabilistic dynamic modeling," Scientia Iranica, vol. 16, no. 1, pp. 87-97, 2009.
[31] D. Prescott and J. Andrews, "Modelling maintenance in railway infrastructure management," in Reliability and Maintainability Symposium (RAMS) Proceedings - Annual, 2013.

[32] L. Podofillini, E. Zio, and J. Vatn, "Risk-informed optimisation of railway tracks inspection and maintenance procedures," Reliability Engineering \& System Safety, vol. 91, no. 1, pp. 20-35, 2006.

[33] Public Transport Corporationin, in Tram Track Maintenance Standards, 1997. 